\section{Pôr em prática a reforma da antiga Academia: dificuldades enfrentadas pela Escola Nacional de Belas Artes (1891-1895)}

\section{CAMILA DAZZI}

Resumo

Este trabalho apresenta uma análise dos primeiros anos da Escola Nacional de Belas Artes, que se desdobram após a aprovação do Decreto no 938, de 8 de novembro de 1890, que instituiu os novos estatutos da instituição. Os estatutos de 1890 reformaram a antiga Academia de Belas Artes e tiveram como objetivo a modernização de seu sistema de ensino artístico. Mas até que ponto era possível fazer as alterações propostas nos estatutos? Quais as dificuldades que a implementação da Reforma de 1890 encontrou? Estas são as principais questões a que vamos responder no nosso artigo.
Palavras-chave:

Escola Nacional de Belas Artes, Reforma de 1890 , ensino artístico 


\section{Put into practice the reform of the old Academy: difficulties faced by the National School of Fine Arts (1891-1895)}

Abstract

This paper presents an analysis of the first years of the National School of Fine Arts that unfold after the approval of the Decree n.938 of November 8, 1890, which established the new statutes of the institution. The statutes of 1890 reformed the old Academy of Fine Arts and aimed the modernization of its artistic education system. But to what extent was possible to make the changes proposed in the statutes? What difficulties the implementation of the Reform of 1890 encountered? These are the main questions that we will

Keywords: strive to answer in the paper. 


\section{Poner en práctica la reforma de la anti- gua Academia: dificultades enfrentadas por la Escuela Nacional de Bellas Artes (1891-1895)}

\section{CAMILA DAZZI}

\section{Resumen}

Este trabajo presenta un análisis de los primeros años de la Escuela Nacional de Belas Artes, que se desdoblan después de la aprobación del Decreto no 938, de 8 de noviembre de 189o, que estableció los nuevos estatutos de la institución. Los estatutos de 1890 reformaron la antigua Academia de Bellas Artes y tuvieron como objetivo la modernización de su sistema de enseñanza artística. Pero hasta qué punto era posible hacer las modificaciones propuestas en los estatutos? ¿Cuáles son las dificultades que la implementación de la Reforma de 1890 ¿Encontró? Estas son las principales cuestiones a las que vamos a responder en nuestro artículo.

Palabras clave:

Escuela Nacional de Bellas Artes, Reforma de 1890 , enseñanza artística. 
A Reforma de 1890 , que transformou a Academia das Belas Artes em Escola Nacional de Belas Artes, foi até muito recentemente considerada pelos historiadores da arte brasileira, e ainda o é por muitos, como uma mera mudança de rótulo. Estudos recentes têm procurado mostrar que mudanças concretas foram implementadas no sistema de ensino da instituição, visando, sobretudo, a sua modernização, como a tese de doutoramento de Camila Dazzi, defendida em 2011 (DAZZI, 2011). O interesse pela Reforma de 1890 e pelas mudanças dela advindas puderam ser sentidas em 2015, quando o tema foi um dos tópicos debatidos pela primeira vez no VI Seminário do Museu D. João VI - Histórias da Escola de Belas Artes: Revisão Crítica de sua Trajetória. No entanto, os estudos mais consistentes sobre a Reforma de 1890 ainda são raros, e os artigos provenientes destes estudos têm como foco, sobretudo, as mudanças ocorridas no sistema de ensino, como o artigo "Pai e construtor da arte brasileira. A Academia das Belas Artes na reforma da educação promovida por Benjamin Constant em 1890/1891" (DAZZI, 2013), e não os entraves enfrentados pelo diretor da instituição, Rodolpho Bernardelli, para implementar as novas propostas que passaram a vigorar. Afinal, que dificuldades foram encontradas para pôr em prática a reforma? A tarefa não era das mais fáceis, como desabafou Rodolpho Bernardelli, em seu relatório ao ministro da Justiça:

Senhor Ministro, chamado em novembro de 1890 para assumir a respectiva direcção e por em pratica a reforma da antiga Academia de Bellas Artes, instituição caduca e que nenhum desenvolvimento proporcionava à mocidade que se dedicava às artes, aceitei toda a responsabilidade dessa hon- 
rosa incumbência, comprometendo desde então não só minha tranquillidade, como minha reputação artística (BERNADELLI, H., 1895c, p. 231, grifo nosso).

Ao nos determos sobre a documentação disponível acerca dos anos iniciais da Escola Nacional de Belas Artes (1891, 1892, 1893, 1894 e 1895), hoje pertencentes ao Museu Dom João VI da UFRJ, verificamos que a Escola enfrentou inúmeros problemas que dificultaram o bom andamento das aulas ministradas na instituição: das péssimas condições estruturais da edificação na qual estava sediada (ainda o prédio original, projetado por Grandjean de Montigny), passando pela falta de material adequado, à baixa frequência dos alunos. Um conjunto de fatores que levou à insatisfação generalizada, ocasionando a contínua ausência de professores, que solicitavam licenças médicas e até mesmo apresentavam pedidos de exoneração.

No quadro que segue, apresentamos um panorama dos professores que passaram pela instituição ao longo dos seus quatro primeiros anos de funcionamento, suas substituições por licenças médicas e suas exonerações - quase na totalidade, por requerimento dos próprios profissionais.

QUADRO 1 - Professores e cadeiras da Escola Nacional de Belas Artes entre 1891 e 1894

\begin{tabular}{|l|l|l|}
\hline \multicolumn{1}{|c|}{ CADEIRA } & PROFESSOR & \multicolumn{1}{c|}{ PERMANÊNCIA } \\
\hline Mitologia & $\begin{array}{l}\text { Raul } \\
\text { Pompéia }\end{array}$ & $\begin{array}{l}\text { Permaneceu na cadeira até 1895, sem ser substituído. } \\
\text { Faleceu em dezembro do referido ano. }\end{array}$ \\
\hline Estereotomia & $\begin{array}{l}\text { Sante } \\
\text { Bucciarelli }\end{array}$ & $\begin{array}{l}\text { Manteve-se na cadeira até seu falecimento em 1894. } \\
\text { Em maio de 1892, foi transferido para a cadeira de } \\
\text { geometria descritiva, por falta de alunos para cursar } \\
\text { estereotomia. }\end{array}$ \\
\hline $\begin{array}{l}\text { Geometria } \\
\text { descritiva } \\
\text { Perspectiva } \\
\text { e sombras }\end{array}$ & $\begin{array}{l}\text { Sante } \\
\text { Bucciarelli }\end{array}$ & $\begin{array}{l}\text { Aarlos } \\
\text { Cianconi a morte de Bucciarelli, Carlos Cianconi foi } \\
\text { civro de correspondências, 26 mar. 1894, p. 73A.) }\end{array}$ \\
\hline
\end{tabular}

quadro 1. continua 


\begin{tabular}{|c|c|c|}
\hline $\begin{array}{l}\text { Desenho } \\
\text { linear } \\
\text { Noções de } \\
\text { topografia, } \\
\text { plantas e } \\
\text { desenho } \\
\text { topográfico }\end{array}$ & $\begin{array}{l}\text { Henrique } \\
\text { Bahiana } \\
\text { Carlos } \\
\text { Cianconi }\end{array}$ & $\begin{array}{l}\text { Bahiana foi nomeado por decreto de } 30 \text { de dezem- } \\
\text { bro de } 1890 \text { e pediu exoneração da cadeira em } 8 \text { de } \\
\text { novembro de } 1893 \text { (MUSEU D. JOÃO VI, Livro de cor- } \\
\text { respondências } 8 \text { nov. 1893, p. 68A). Cianconi regeu a } \\
\text { cadeira no final do ano letivo de 1894, por indicação e } \\
\text { pedido de Rodolpho Bernardelli. }\end{array}$ \\
\hline $\begin{array}{l}\text { Elementos } \\
\text { da arquitetura } \\
\text { e ornatos }\end{array}$ & $\begin{array}{l}\text { Heitor de } \\
\text { Cordoville }\end{array}$ & $\begin{array}{l}\text { Designado para o cargo por decreto de } 30 \text { de dezem- } \\
\text { bro de } 1890 \text {, nele permaneceu até o seu falecimento, } \\
\text { em } 1904 .\end{array}$ \\
\hline Modelo-vivo & $\begin{array}{l}\text { Modesto } \\
\text { Brocos }\end{array}$ & $\begin{array}{l}\text { Substituiu Zeferino da Costa desde a abertura da } \\
\text { Escola, em 1891, até agosto de 1893. Após o pedido de } \\
\text { exoneração de Zeferino da Costa, em agosto de } 1893 \text {, } \\
\text { assumiu a cadeira definitivamente. Modesto Brocos } \\
\text { não apresentou pedidos de licença, sendo ele o único } \\
\text { professor da cadeira de } 1891 \text { a 1894. Zeferino da Costa } \\
\text { não chegou a reger a cadeira de modelo-vivo ao longo } \\
\text { desses quatro anos. }\end{array}$ \\
\hline $\begin{array}{l}\text { Desenho } \\
\text { figurado }\end{array}$ & $\begin{array}{l}\text { Pedro } \\
\text { Weingärtner } \\
\text { Modesto } \\
\text { Brocos } \\
\text { Belmiro de } \\
\text { Almeida }\end{array}$ & $\begin{array}{l}\text { Pedro Weingärtner assumiu a cadeira em 1891. Ao } \\
\text { longo de 1892, solicitou algumas licenças. Em } 28 \text { de } \\
\text { maio de } 1893 \text {, requereu uma licença prolongada, su- } \\
\text { cedida por outras, retornando à instituição somente } \\
\text { em setembro de } 1894 \text {. Modesto Brocos ministrou } \\
\text { a disciplina de maio a agosto de } 1893 \text {. Belmiro de } \\
\text { Almeida permaneceu na cadeira de agosto de } 1893 \text { até } \\
\text { um mês antes do retorno de Pedro Weingärtner. }\end{array}$ \\
\hline Pintura & $\begin{array}{l}\text { Henrique } \\
\text { Bernardelli }\end{array}$ & $\begin{array}{l}\text { Foi nomeado por decreto de } 30 \text { de dezembro de } 1890 \text {. } \\
\text { Permaneceu na cadeira até 1894, mas se ausentou em } \\
\text { licença durante longo período, sendo substituído de } \\
\text { junho de } 1893 \text { a outubro de } 1894 \text { por Rodolpho Amo- } \\
\text { êdo e Modesto Brocos (AMOÊDO, 1894, p. 28). }\end{array}$ \\
\hline Pintura & $\begin{array}{l}\text { Rodolpho } \\
\text { Amoêdo }\end{array}$ & $\begin{array}{l}\text { Designado para a cadeira por decreto de } 30 \text { de } \\
\text { dezembro de } 1890 \text {, nela se manteve até 1894, sem } \\
\text { apresentar pedidos de licença. Em fevereiro de 1893, } \\
\text { assumiu a direção da Escola Nacional de Belas Artes, } \\
\text { durante a ausência de Rodolpho Bernardelli, cargo no } \\
\text { qual permaneceu até setembro de } 1894 \text {. }\end{array}$ \\
\hline
\end{tabular}




\begin{tabular}{|c|c|c|}
\hline $\begin{array}{l}\text { Química, } \\
\text { física e } \\
\text { história } \\
\text { natural }\end{array}$ & $\begin{array}{l}\text { Cincinato } \\
\text { Lopes } \\
\text { Márcio } \\
\text { Filafiano } \\
\text { Nery }\end{array}$ & $\begin{array}{l}\text { Foi nomeado por decreto de } 22 \text { de abril de } 1891 \text {; licen- } \\
\text { ciou-se em } 1894 \text {, sendo exonerado, por abandono de } \\
\text { emprego, em } 25 \text { de maio desse mesmo ano. Nery foi } \\
\text { nomeado por decreto de } 7 \text { de novembro de } 1894 \text {, mas, } \\
\text { desde o início do referido ano, lecionou a disciplina } \\
\text { como professor substituto. }\end{array}$ \\
\hline $\begin{array}{l}\text { Anatomia } \\
\text { e fisiologia } \\
\text { das paixões }\end{array}$ & $\begin{array}{l}\text { Azevedo } \\
\text { Macedo } \\
\text { Francisco } \\
\text { Fajardo }\end{array}$ & $\begin{array}{l}\text { Nomeado por decreto de } 30 \text { de dezembro de } 1890 \text {, } \\
\text { permaneceu na cadeira até } 25 \text { de julho de } 1893 \text {, quan- } \\
\text { do faleceu; sendo substituído por Francisco Fajardo, } \\
\text { em agosto de } 1893 \text {. }\end{array}$ \\
\hline $\begin{array}{l}\text { História } \\
\text { da arte }\end{array}$ & $\begin{array}{l}\text { Medeirose } \\
\text { Albuquerque } \\
\text { Gonzaga } \\
\text { Duque Estrada } \\
\text { Henrique } \\
\text { Coelho Netto } \\
\text { Urbano } \\
\text { Duarte de } \\
\text { Oliveira }\end{array}$ & $\begin{array}{l}\text { Medeiros e Albuquerque foi designado para a cadeira } \\
\text { por decreto de zo de dezembro de } 189 \text { o. Permane- } \\
\text { ceu em licença por inúmeros períodos ao longo de } \\
\text { 1891, 1892, } 1893 \text { e } 1894 \text {. Pediu exoneração em junho } \\
\text { de 1894, sendo substituído por Urbano Duarte de } \\
\text { Oliveira, que, logo em seguida, pediu exoneração da } \\
\text { cadeira, a qual foi assumida por Henrique Coelho } \\
\text { Netto. Gonzaga Duque serviu interinamente em 1891; } \\
\text { foi exonerado a pedido em } 26 \text { de maio desse mesmo } \\
\text { ano. }\end{array}$ \\
\hline $\begin{array}{l}\text { História e } \\
\text { teoria da } \\
\text { arquitetura }\end{array}$ & $\begin{array}{l}\text { Carlo } \\
\text { Parlagreco }\end{array}$ & $\begin{array}{l}\text { Contratado na Itália, em setembro de } 1891 \text { (MUSEU } \\
\text { D. JOÃO VI, Livro de correspondências, } 16 \text { nov. } \\
\text { 1891. Contrato de } 29 \text { set. 1891. p. } 20 \text { A e B, } 21 \text { A e B), } \\
\text { permaneceu na cadeira até 1894, sendo o seu único } \\
\text { professor. }\end{array}$ \\
\hline $\begin{array}{l}\text { Arqueologia } \\
\text { e etnografia }\end{array}$ & $\begin{array}{l}\text { Charles } \\
\text { Gustave } \\
\text { Paille }\end{array}$ & $\begin{array}{l}\text { Nomeado em Paris (MUSEU D. JOÃO VI, Livro de } \\
\text { correspondências, } 13 \text { abr. 1892. Contrato de } 8 \text { mar. } \\
\text { 1892. p. 32A e B), em março de 1892, teve o contrato } \\
\text { renovado em 1893. Foi dispensado da cadeira por } \\
\text { visto de } 24 \text { de novembro de } 1893 \text {. A cadeira não foi } \\
\text { ocupada posteriormente, sendo extinta. }\end{array}$ \\
\hline
\end{tabular}




\begin{tabular}{|l|l|l|} 
Escultura & $\begin{array}{l}\text { Rodolpho } \\
\text { Bernardelli }\end{array}$ & $\begin{array}{l}\text { Foi nomeado diretor da Escola em novembro de 1890 } \\
\text { e professor de escultura da mesma instituição em } \\
\text { dezembro de 1890. Até 1894, foi o único professor } \\
\text { da cadeira, se ausentando das duas funções entre } \\
\text { fevereiro de } 1893 \text { e setembro de } 1894 .\end{array}$ \\
\hline
\end{tabular}

FONTE: Acervo do Museu D. João VI/EBA/UFRJ e GALVÃO, Alfredo. Subsídios para a história da Academia Imperial e da Escola Nacional de Belas Artes. Rio de Janeiro, 1954.

Uma das primeiras dificuldades enfrentadas pelos professores da Escola Nacional de Belas Artes foi a falta de material para as aulas. Este, que pode parecer um problema banal, aos professores da Escola se caracterizava como um entrave. Como estabelecer uma escola moderna de arte, do modo que pretendia a Reforma de 1890, se não havia sequer material adequado para o andamento das aulas? Provavelmente, esta tenha sido a primeira decepção dos professores recém-nomeados e contratados, que começaram a atuar na instituição em 1891.

Em diferentes momentos, os professores reclamaram do exímio material com que contavam para as suas aulas, material esse não disponível no Brasil, tendo de ser encomendado da Europa.

Como diretor da Escola Nacional de Belas Artes, Rodolpho Bernardelli tinha conhecimento dessa dificuldade e procurou saná-la, sem, no entanto, obter grande sucesso. Em 9 de novembro de 1891, Bernardelli solicitou a compra do material necessário às aulas, além de livros e revistas, através de uma encomenda feita a Zeferino da Costa, que se encontrava na Itália (MUSEU D. JOÃO VI, Livro de correspondências, 9 nov. 1891, p. 20A). Pelo mesmo livro de correspondências consultado, temos conhecimento que Zeferino da Costa pagou o material com recursos próprios, sendo posteriormente reembolsado pelo governo brasileiro.

A dificuldade, porém, não foi plenamente sanada com a encomenda a Zeferino da Costa, pois, no relatório ao ministro da Justiça sobre o ano letivo de 1893, encontramos, nos pequenos relatórios individuais de alguns professores da Escola, reclamações sobre a falta de material.

Rodolpho Amoêdo, vice-diretor da Escola, que em 1893 ocupava os cargos de diretor - devido ao afastamento de Rodolpho Bernardelli para a participação na Exposição Internacional de Chicago daquele ano -, e de professor de pintura, e Modesto Brocos, que assumiu uma das cadeiras de pintura durante a ausência de Henrique Bernardelli, que também estava afastado, queixaram-se da falta de material, sobretudo, de "costumes antigos ou feitos se- 
gundo figurinos antigos" e reforçaram as vicissitudes pelas quais passavam ao comentar que 'retalhos [serviam] como 'fundo' ao atelier" (AMOÊDO, 1894, p. 28).

Também o professor da cadeira de história natural, física e química, Márcio Nery, apresentou em seu pequeno relatório de 1894, as péssimas condições em que ocorriam as suas aulas, em razão da ausência de material adequado. Márcio Nery tentou convencer o governo sobre a gravidade de ministrar uma disciplina de "noções concretas de ciências naturaes" quando, como únicos materiais de ensino, "só havia uns cartazes mal desenhados de botanica e zoologia e umas três amostras de rochas para o estudo da zoologia" (NERY, 1895, p. 22-24).

A falta de material adequado para as aulas, que ia desde tintas, passando por figurinos antigos, até cartazes e mostras de minerais, nos permite compreender que a Escola Nacional de Belas Artes não recebia do Ministério da Instrução Pública e, posteriormente, do Ministério da Justiça a verba necessária para a sua manutenção e o seu bom andamento. Em parte, essa indiferença pode ser atribuída ao momento político de instabilidade. Devemos recordar que Benjamin Constant fora retirado da direção do Ministério da Instrução Pública, vindo a falecer logo em seguida. Sem sombra de dúvidas, Benjamin Constant era a pessoa que poderia intervir junto ao governo em favor da instituição, e a sua ausência acarretou alguns problemas que, após intensa pesquisa, passamos a nos dar conta.

Outra dificuldade enfrentada pelos professores da Escola e, por que não dizer, por seu diretor dizia respeito às condições de higiene da cidade do Rio de Janeiro. As constantes epidemias afastavam professores e alunos da capital e determinavam mudanças no calendário escolar. Somava-se a isso o clima de instabilidade política que vigorou nos primeiros anos da década de 1890, determinando revoltas que tiveram como palco a cidade carioca.

Em 1891, ano em que a nova Escola Nacional de Belas Artes foi aberta, as aulas tardaram a ter início em razão da epidemia de varíola na capital federal. O governo teve de tomar medidas repressivas contra a população miserável que vivia amontoada em cortiços na periferia da cidade, em condições negativas de higiene e alimentação - hospedeira natural de doenças contagiosas que eram tratadas, por conseguinte, com o isolamento total do doente do seu meio familiar e social. Os carroções do serviço sanitário recolhiam os enfermos como animais, enquanto os homens do desinfetório procediam a um expurgo total na casa do varioloso (MENDES JR.; MARANHÃO, 1981, p. 292).

Nesse contexto, as escolas permaneceram fechadas, e o ano letivo só teve início em abril, mesmo assim com interrupções 
frequentes em decorrência da epidemia. A frequência às aulas na capital federal diminuía progressivamente na medida em que os alunos tinham familiares atingidos pela doença.

Acreditamos que não deva ter sido diferente o que se deu na Escola Nacional de Belas Artes. De fato, na instituição, as aulas do ano de 1891 só foram iniciadas em junho (MUSEU D. JOÃO VI, Ata de 4 jun. 1891, p. 2B).

Nas atas, nos livros de correspondência e nos relatórios ministeriais, há menção a datas modificadas em razão das péssimas condições higiênicas da cidade do Rio de Janeiro. Em 1892, por exemplo, a Inspetoria Geral de Higiene, por aviso de $1^{\circ}$ de março de 1892, notificou que o início das aulas deveria ser adiado para 15 de abril (MUSEU D. JOÃO VI, Livro de correspondências, $1^{\circ}$ mar. 1892, p. 30A). No entanto, o tempo determinado pela Inspetoria de Higiene parece não ter sido suficiente, pois, na reunião do Conselho Escolar, de 6 de abril de 1892, os professores desejavam solicitar ao governo o adiamento das aulas para $1^{\circ}$ de maio, em função do "mau estado sanitário que continua nessa capital" (MUSEU D. JOÃO VI, Ata de 6 abr. 1891, p. 12A).

As salas de aula eram igualmente um constante problema, algo que só seria sanado com a transferência da Escola para o seu novo prédio, em 1908 - o qual abriga atualmente o Museu Nacional de Belas Artes. As reclamações sobre o antigo prédio incluíam falta de iluminação, sobretudo em relação às disciplinas que deveriam ocorrer à noite, salas que precisavam ser compartilhadas por professores e insalubridade dos ambientes.

Desde maio de 1891, antes mesmo de as aulas terem início naquele que seria o primeiro ano de funcionamento da Escola Nacional de Belas Artes, Rodolpho Bernardelli apontou o fato de que as mudanças propostas pelos estatutos não seriam suficientes, eram necessárias também melhores salas de aula no que se referia à iluminação:

Para os trabalhos escolares a insufficiencia da casa é ainda mais de sentir. $\mathrm{O}$ numero das salas communs é insignificante, faltam absolutamente as salas especiaes. Não ha, um atelier que assim se possa chamar, porque a luz de 45 gráos que realça os modelos, é impossível do obter entre as estreitas paredes. A sala no rez do chão, onde se faz o curso do desenho de figura, vagamente aclarada por altos retabulos envidraçados, impressiona tristemente como um subterraneo. Tem geralmente de vegetar na sombra uma especialidade de ensino que, bem sabeis, depende mais de um feliz reflexo de sol do que da doutrina de todos os compendios (BERNARDELLI, R., 1891, p. 20-21). 
A instalação de luz elétrica no prédio da Escola, ao mesmo tempo em que significou um avanço para a boa realização das aulas noturnas, foi sinônimo de problema para as aulas que ocorriam durante o dia. $\mathrm{O}$ pedido de instalação da eletricidade partiu dos professores das disciplinas teóricas, que desejavam usar em suas aulas projetores de imagens.

Rodolpho Amoêdo, então vice-diretor da Escola, em seu relatório sobre o ano letivo de 1893 elucidou como ocorriam as aulas noturnas:

Attendendo à falta de capacidade no actual edifício da Escola e à necessidade absoluta de funccionarem a noite as aulas de Archeologia e Ethnographia e Historia e Theoria da Architectura, nas quaes se teriam de fazer projecções com luz electrica, necessaria ao desenvolvimento dessas materias, em solução ao officio desta directoria, n. 504 de 19 de abril [de 1893], foi autorisado, por aviso n. 372 de 29 desse mez do Ministerio a vosso cargo, o funccionamento nocturno daquellas aulas, como medida provisoria, assim como das de desenho de modelo-vivo, mythologia e historia das artes; ficando assim atendido um dos reclamos que a directoria desta Escola teve occasião de dirigir ao Governo no relatorio de 1891.

Em maio começaram os trabalhos desses cursos. A aula de desenho de modelo-vivo funccionou em uma das salas do pavimento superior e os cursos theoricos na n. 3, onde se montaram os aparelhos para as alludidas projeções. Tanto esta sala, como a galeria foram illuminadas a luz electrica.

Nos cursos de Archeologia e Ethnographia e Historia e Theoria da Architectura os respectivos professores realisaram interessantes e instructivas demonstrações com auxílio da luz electrica (AMOÊDO, 1894, p. 5-7).

Vemos, assim, que, com a instalação da luz elétrica e a mudança para o turno da noite de disciplinas como modelo-vivo e desenho figurado, na medida do possível, as exigências foram sanadas. No entanto, ainda em 1893, a disciplina de desenho figurado funcionava durante o dia, como nos deixa saber o pequeno relatório de Belmiro de Almeida, datado daquele ano:

Esse local não pode absolutamente convir para o ensino do desenho; a luz que illumina não é directa como convem para esse mister, é luz de reflexo, que varia alternadamente de instante a instante, prejudicando em muito as lições do profes- 
sor. Tive muitas vezes ao começar a lição o modelo illuminado de um modo e momentos depois de modo muito diverso. Ora, V. Ex. [...] deve compreender que é impossível ensinar convenientemente os principios de claro-escuro em um local que não tenha luz directa, constante, nas horas de lição (ALMEIDA, 1894, p. 19-20).

De fato, somente as disciplinas teóricas e a disciplina de modelo-vivo passaram a funcionar no período noturno. Mas havia ainda outros problemas no prédio da Escola. A fiação elétrica era periodicamente trocada em razão de problemas de instalação e mau funcionamento - as aulas noturnas só poderiam ser ministradas com a fiação em perfeito estado (MUSEU D. JOÃO VI. Livro de correspondências, 25 abr. 1894, p. 74A). Isso significou atraso no início das aulas noturnas, pois reparos e reinstalação da fiação elétrica de uma instituição federal, nos anos de 1890, eram um processo tão burocrático como nos dias atuais.

Em 1893, o início das aulas de modelo-vivo foi adiado para $1^{\circ}$ de maio, um mês depois do princípio do ano letivo (NASCIMENTO, 1894, p. 253). Em 1894, as aulas comuns começaram em 15 de maio, porém, as aulas de modelo-vivo foram iniciadas em 4 de junho, "em consequencia de só ter funcionado de $31 \mathrm{em}$ diante a luz eletrica" (BERNARDELLI, 1895, p. 2).

Dessa maneira, se, em parte, a instalação da luz elétrica conduzia a Escola Nacional de Belas Artes à modernidade, significando melhoria considerável à sua estrutura, por outro lado, a mesma instalação acarretava problemas graves.

Modesto Brocos e Rodolpho Amoêdo, que compartilhavam a mesma sala, relataram as dificuldades por eles encontradas em consequência de tal partilha:

Quanto a aula que lecciono devo reclamar não só quanto à má distribuição da luz eletrica, mas tambem quanto ao funccionamento de uma das aulas de pintura na mesma sala, o que muito prejudica o bom andamento da minha aula. Saúde e fraternidade. - Modesto Brocos (BROCOS, 1895, p. 17).

Rodolpho Amoêdo, em relatório similar, insistiu nas mesmas contrariedades:

Todos os annos somos obrigados a registrar o pessimo local em que funcciona a aula de pintura [...]. Além do mao local, acresce que nelle funcciona tambem a aula de modelo-vivo, que necessita de instalação de luz eletrica, que não é possível 
remover durante o dia, constitue isso um estorvo para ambas as aulas (AMOÊDO, 1895, p. 18).

De todas as disciplinas que enfrentavam transtornos, parece ter sido a de desenho figurado a que mais sofreu. Desenho figurado era uma disciplina basilar na estrutura educacional da Escola Nacional de Belas Artes, estando presente nos três primeiros anos do curso geral, que depois se dividia nos cursos específicos de pintura, escultura, arquitetura e gravura. Deveria, portanto, ser desenvolvida nas melhores condições possíveis.

No entanto, as queixas de Pedro Weingärtner, primeiro professor a lecionar a disciplina na Escola, eram constantes. Ousamos concluir que as péssimas condições de suas aulas contribuíram para os pedidos de licença que efetuou no período entre 1893 e setembro de 1894 e, finalmente, para o seu desligamento definitivo da Escola, em maio de 1895. Também os professores que o substituíram ao longo de suas ausências por licença - Brocos, entre 2 de maio e 6 de agosto de 1893, e Belmiro de Almeida, entre agosto de 1893 e julho de 1894 - expuseram em relatórios problemas similares aos apontados por Weingärtner.

Uma das primeiras queixas de Pedro Weingärtner está no ofício datado de 26 de junho de 1892, no qual o artista, expondo os motivos das suas reclamações, chegou a solicitar um auxiliar (MUSEU D. JOÃO VI, Livro de correspondências, 26 jun. 1892. p. 36B), passando por cima da aprovação do Ministério da Instrução Pública.

Os problemas enfrentados pela disciplina não foram atenuados ao longo de 1893. Após a saída de Weingärtner, que permaneceu em licença por aproximadamente um ano, Belmiro de Almeida assumiu a cadeira de desenho figurado. O grande número de alunos nas aulas também para ele se configurava como um grave problema. Justamente por ser uma disciplina de base, que fundamentalmente ensinava a desenhar, havia maior número de alunos interessados em cursá-la, sobretudo alunos de livre frequência.

Assim comentou Belmiro de Almeida em seu pequeno relatório de 1893:

Se consegui, como acima digo, bons resultados, foi porque, sendo o numero de frequência muito limitado [devido a Revolta da Armada] pude espalhar os Srs. alumnos por diversos pontos do estabelecimento; mas isso não será sempre possível, attendendo a que o numero de frequencia em época normal será maior e que tambem o numero de matriculados deve crescer; o local não comportará esse numero, assim 
como um só professor não poderá leccionar convenientemente, pois, para tanto, será preciso para cada 20 alumnos um professor. V. Ex. não ignora, que a classe de desenho não é uma aula oral, onde o professor tanto fala para um como para mil alumnos; em uma aula de desenho o professor criterioso tem de dar a cada alumno a lição de fórma diversa e consentânea com o gráo de conhecimentos e intelligencia de cada um delles e estudar com attenção suas tendencias naturaes. Não é, pois, em tres horas de aula o horario da classe de desenho figurado é das nove horas da manhã ao meio dia - que um só professor poderá dar 70 lições proveitosas (ALMEIDA, 1893, p. 19-20, grifo nosso).

Os argumentos de Belmiro de Almeida não poderiam ser melhores. Eles nos apresentam um professor consciente do seu trabalho e, mais, nos revelam um Belmiro de Almeida que, como mestre, levou em consideração a individualidade dos alunos, os diferentes graus de conhecimento e a capacidade de assimilação de novos conteúdos. Justamente por essa nova forma de compreender o papel do professor - que, acreditamos, era compartilhada pelos demais docentes da Escola Nacional de Belas Artes -, tornava-se impossível ministrar uma disciplina prática para 70 alunos, entre as nove da manhã e o meio-dia. Isso marca uma mudança no pensamento pedagógico do ensino de arte.

Se não era possível a contratação de um auxiliar para as aulas de desenho figurado, que se criasse então uma segunda cadeira da disciplina, a exemplo das duas cadeiras de pintura que a Escola possuía. Esta foi a proposta de Fernando Lobo (1893, p. 213), ministro da Justiça e Negócios Interiores, em seu relatório ao vice-presidente Floriano Peixoto, sobre o ano de 1892.

Vemos, portanto, que as melhorias relacionadas ao curso de desenho figurado não foram ignoradas pelo poder público, porém, as condições debilitadas do governo republicano, acompanhadas pela instabilidade política, podem ter contribuído para uma desatenção do vice-presidente em relação à nova Escola Nacional de Belas Artes.

Os ambientes insalubres das salas de aula e dos ateliês - que foram considerados como possíveis contribuidores da piora do estado de saúde de um aluno e da sua consecutiva morte (MUSEU D. JOÃO VI, Ata de 25 set. 1891, p. 8) - também eram motivo de reclamações constantes.

É natural lermos em relatórios comentários como o que segue, de autoria do então diretor interino da Escola, Rodolpho Amoêdo: 
Resulta d'ahi grand embaraço no funcionamento dos diversos ateliers, que foram estabelecidos em salas impróprias, humidas, sem ar e sobretudo sem luz, por falta de acomodações convenientes neste edifício. [...] Urge Sr. Ministro, que providenciaeis para que os ateliers sejam estabelecidos em local apropriado, embora fora do edifício da Escola, contanto que os trabalhos possam fazer-se nas condições exigidas pela bôa thechica e pela hygiene (AMOEDO, 1893, p. 16, grifo nosso).

Ou, ainda, ponderações como a de Henrique Bernardelli, professor de pintura:

Mais de uma vez tive ocasião de fazer notar o defeituoso e insufficiente local que possuimos como aulas. Esse defeito de termos quartos sem hygiene para o desenvolvimento do cheiro das tintas, nem condições apropriadas para o estudo da pintura [...] faz pedir aos alumnos a boa vontade, e ao professor esforços [...] (BERNARDELLI, H., 1895c, p. 17-18).

Péssima iluminação, falta de higiene e salas de aula inadequadas eram problemas que poderiam ser facilmente resolvidos com a construção de um novo prédio para a Escola Nacional de Belas Artes. Na impossibilidade de edificação de um novo prédio, era plausível que, ao menos, a Escola fosse transferida para um lugar mais adequado. Verificamos que os dois pedidos foram oficializados por Rodolpho Bernardelli e por Rodolpho Amoêdo, este último como vice-diretor, ocupando interinamente o cargo de diretor.

A análise dos documentos referentes à Escola nos revela que Sante Bucciarelli - arquiteto italiano que lecionou as disciplinas de estereotomia e geometria descritiva, perspectiva e sombras - elaborou o projeto de uma Escola Nacional de Belas Artes, aceito, inclusive, pelo governo (AMOÊDO, 1894, p. 16). Portanto, desde o primeiro momento de criação da instituição, seus professores estavam envolvidos na concepção de um novo espaço para a Escola.

Em um ofício de 21 de janeiro de 1895, Rodolpho Bernardelli, cansado de solicitar a construção de um prédio novo para a instituição, mas não totalmente derrotado, fez uma solicitação ao ministro da Justiça e Negócios Interiores, Antonio Gonçalves Ferreira, na qual requereu a transferência da Escola para um novo imóvel: 
Por circunstâncias que cada dia se tornam mais difíceis, vejo-me obrigado dirigir-vos este officio afim de pedir vossa esclarecida attenção, para um assumpto, que considero de grande importancia e urgente solução. Senhor Ministro, chamado em novembro de 1890 para assumir a respectiva direcção [...] pus maos a obra; não o fiz, porem, sem fazer ver ao pranteado Dr. Benjamin Constant a necessidade de ser removida a Escola do lugar onde funcionava, para que, com proveito e rapidez se pudesse desenvolver o programa do ensino artístico que deve guiar os jovens artistas. Prometeu attender ao meu pedido o saudoso brasileiro, mas infelizmente a morte ceifou essa grande individualidade, e desde essa época não tenho deixado de pedir em relatórios e conferencias a providencia da mudança da Escola, havendo chegado a apresentar os planos e o orçamento de um novo edifício. [...] O que solicito hoje não é mais a construcção de um novo edificio, porque a despesa seria enorme e o tempo urge; mas, sim, a concessão do edificio da Praça do Mercado da Glória, situado no Catete, que apesar de não ter caráter algum arquitetônico, viria a satisfazer perfeitamente a installação da Escola. [...] Invoco toda a sua attenção e o vosso patriotismo para este assumpto, porque delle só depende hoje a vida deste estabelecimento [...] (BERNARDELLI, R., 1895b, p. 231-232, grifo nosso).

O pedido de Rodolpho Bernardelli não terminava aí, seguia um relato das péssimas condições do prédio onde a Escola funcionava. Segundo o próprio Bernardelli, o vice-presidente da República, Floriano Peixoto, havia se interessado pela construção de um novo prédio, tendo, em sua "Mensagem no Congresso Nacional" de 1893, indicado "aos Srs. Representantes da Nação a utilidade de decretar verba para a construção de um novo edifício para a Escola” (BERNARDELLI, 1895b, p. 231-232).

Em um momento de crise nacional, mencionar a Escola Nacional de Belas Artes na chamada "Mensagem de 1893" não era algo destituído de importância. Havia interesse concreto no pleno funcionamento da Escola, o que só seria possível em uma nova edificação. Faltava, no entanto, a verba necessária e, mesmo, tranquilidade política para que o governo se dedicasse à melhoria do ensino da arte no país.

Assim, as dificuldades encontradas por professores, alunos e gestores da Escola obstavam a implementação da Reforma de 1890 . Para agravar a situação, muitas vezes, os profes- 
sores se viam de "pés e mãos atados", impossibilitados de agir em razão de inúmeros detalhes burocráticos.

Em 1893, por exemplo, diante da necessidade de ocupação das cadeiras vagas da Escola, pondo fim ao problema das disciplinas sem docentes, o conselho escolar precisava criar um regulamento para os lugares de professores da instituição (MUSEU D. JOÃO VI, Ata de 19 jul. 1893, p. 22B). A tarefa se constituiu como algo quase impossível, em função da confusa legislação estabelecida no Código de Instrução. Os professores não sabiam como agir, não sabiam o que era ou não possível. As suas dúvidas se apresentavam como típicas de um contexto caracterizado por um novo regime político, que então se estabelecia, período em que normas, leis, regulamentos e decretos eram substituídos com facilidade.

No final do período por nós estudado, a situação da Escola piorou depois que Prudente de Morais tomou posse como presidente da República, em novembro de 1894. Seu governo não foi dos mais favoráveis às artes, sobretudo no que tange à Escola Nacional de Belas Artes.

Pudemos verificar, em cartas destinadas por Henrique Bernardelli a Eliseu Visconti, entre dezembro de 1894 e fevereiro de 1895 , que o clima político não era dos mais auspiciosos. Henrique Bernardelli descreveu Prudente de Morais como indiferente aos problemas da Escola, esquivando-se de enviar à Europa os dois vencedores do Prêmio de Viagem daquele ano: Bento Barbosa, com o Grande Prêmio de Viagem, e Baptista da Costa, com o Prêmio de Viagem da Exposição Geral. Também atribuiu a Prudente de Morais a morosidade na aquisição das telas selecionadas pelo conselho escolar para compor a Galeria Nacional. Henrique Bernardelli chegou a mencionar, em sua carta de dezembro de 1894, que Rodolpho Bernardelli pediria demissão se a situação da Escola não melhorasse: "Mas essa oposição, se em breve não se dissipar, provocará muito provavelmente a demissão do nosso diretor, o que eu desejo ardentemente como a minha" (BERNARDELLI, H., 1894, s/p).

Nas cartas seguintes a Eliseu Visconti, Henrique Bernardelli apresentou um quadro ainda mais complexo de oposição a Rodolpho Bernardelli e, portanto, à Escola Nacional de Belas Artes. O principal opositor era Cosme Peixoto, que criticava duramente Rodolpho Bernardelli, como diretor e professor, em seus artigos publicados na coluna "Folhetim", do Jornal do Brasil. Mas não só em relação à arte Bernardelli era condenado, calúnias eram disseminadas sobre as suas inclinações políticas: 
Terás lido a campanha que abriram os Cosmes contra nós. Não imaginas as calúnias que contra nós inventam. Só esta te pode dar uma idéia: eles espalharam que o Fofo [Rodolpho Bernardelli] tinha dado dinheiro ao Angelo para ele montar um jornal (o D. Quixote) cujo fim terá de fazer propaganda para a restauração. O Berninha é o reporter dos Cosmes, breve eles terão o outro que está lá, mas eles hão de morrer como os escorpiões (BERNARDELLI, H., 1895, s/p).

Ser acusado de colaborar financeiramente para um jornal que tinha como principal função a restauração do Império e o retorno dos Bragança, ainda que a notícia fosse duvidosa e não apresentasse provas concretas, era o suficiente, no contexto político brasileiro do início da República, para despertar a antipatia e mesmo a inimizade de figuras importantes do governo republicano. Devemos recordar, ainda, que a Escola Nacional de Belas Artes dependia, inteiramente, desse governo, cujo seu diretor era acusado publicamente de querer derrubar. Por certo, o apoio financeiro à Escola tendia a ser prejudicado diante de tais fatos, sobretudo, no que tange à melhoria de suas instalações.

\section{Licenças, exonerações e substituições}

A constante substituição de professores, ocasionada, em grande parte, pelas dificuldades acima mencionadas, também foi um problema que a Escola Nacional de Belas Artes teve que enfrentar nos seus primeiros anos de funcionamento. Professores de várias disciplinas, por diversos motivos, pediram exoneração. Muitas outras disciplinas tiveram seus professores ausentes por mais de um ano em função de licenças médicas. Em ambos os casos, as disciplinas passaram a ser ministradas por professores substitutos, que podiam já lecionar na Escola ou ser contratados temporariamente.

Através da análise de documentos, teses e dissertações, sabemos que parte do corpo docente que foi nomeado para atuar nos primeiros anos de funcionamento da Escola, já se conhecia de longa data. Alguns dos professores estabeleceram amizade ainda no Brasil, como alunos da Academia (foi o caso de Belmiro de Almeida, dos Bernardelli e de Rodolpho Amoêdo), outros estabeleceram contato na Europa, quando realizaram suas estadias de estudo no Velho Mundo (Pedro Weingärtner e Modesto Brocos conheceram os Bernardelli na Itália). É igualmente conhecido que parte desse corpo docente estava, ao longo dos anos finais da 
década de 1880, envolvida com as críticas direcionadas à antiga Academia, tendo alguns contribuído para a Reforma de 1890.

Esses dados nos levam a crer que o grupo de professores assumiu as suas respectivas cadeiras na Escola Nacional de Belas Artes com grande entusiasmo e esperança de que os problemas apresentados pela velha Academia pertencessem ao passado. Era, afinal, uma oportunidade de participarem da constituição de uma escola de arte moderna em território nacional.

Acreditamos, nesse sentido, que os integrantes do núcleo inicial de professores dos ateliês da Escola formavam um grupo seleto: artistas jovens, que haviam estudado no exterior e eram tratados pelos críticos de arte atuantes no Rio de Janeiro na década de 1880 como os iniciadores de uma escola moderna de arte.

É o que justifica a escolha de Pedro Weingärtner para reger a cadeira de desenho figurado em janeiro de 1891, em substituição ao antigo professor da referida cadeira nos tempos da Academia: José Maria de Medeiros. Medeiros não era tão novo, tendo nascido em 1849, fazia parte do corpo docente da antiga Academia e nem de longe era festejado pelos críticos.

De fato, não faria sentido a sua nomeação, pois Pedro Weingärtner havia sido designado em 11 de maio de 1891 para aquele cargo. Mesmo durante os longos períodos de ausência de Pedro Weingärtner por licença médica, a direção da Escola optou por convocar Belmiro de Almeida e não José Maria de Medeiros para substituí-lo. Esses dados reforçam a existência de uma "seleção" de professores para atuação na Escola, que se dava não somente por sua capacidade, mas igualmente por apresentarem um perfil que correspondia aos anseios de modernidade do meio artístico carioca.

Assim, o grupo de professores selecionado para atuar nos primeiros anos da Escola Nacional de Belas Artes tinha uma definição, uma unidade: artistas jovens cujos trabalhos seguiam uma orientação que divergia das "velhas regras" e que eram tidos pela crítica como iniciadores da arte moderna nacional - Henrique Bernardelli, Rodolpho Amoêdo, Pedro Weingärtner, Modesto Brocos, Belmiro de Almeida e o próprio Rodolpho Bernardelli.

Era importante nos anos iniciais da Escola, de afirmação da instituição, conquistar críticas positivas. Até mesmo a nomeação de Zeferino da Costa, professor que havia lecionado na Academia, se justificava plenamente. Embora de uma geração mais velha, desde um primeiro momento, Zeferino da Costa havia se colocado ao lado dos "novos" e contra os "velhos" da Academia (CAVALCANTI, 2007, s/p).

Mas nem mesmo o fato de o núcleo inicial de professores da Escola Nacional de Belas Artes ser coeso foi suficiente para fazer 
com que alguns deles suportassem as dificuldades, sobretudo estruturais, pelas quais passava a instituição - e que evidenciavam a falta de empenho por parte do governo. Tais adversidades levaram a pedidos sucessivos e prolongados de licenças para tratamento de saúde - das quais questionamos a veracidade - e mesmo a pedidos de exoneração, tão logo melhor oportunidade surgia.

Os pedidos de licença fizeram com que cadeiras ficassem vagas e, para as aulas não serem interrompidas, era necessária a inclusão de professores substitutos. Foram muitas as substituições ao longo dos quatro primeiros anos de funcionamento da Escola Nacional de Belas Artes e nem todas ocorreram sem prejuízo aos alunos.

Em junho 1893, o professor de história natural, física e química, Cincinato Américo Lopes, afastado por licença de saúde, foi substituído pelo professor de história da arte, José Joaquim de Campo da Costa de Medeiros e Albuquerque (MUSEU D. JOÃO VI, Livro de correspondências, 10 jun. 1893, p. 22A). A cadeira de história natural, física e química requeria conhecimentos bastante específicos, como nos deixa saber o pequeno relatório de Márcio Nery, professor que assumiu a disciplina, primeiramente como contratado e depois como efetivo, em 1894:

Nomeado por portaria de 27 de maio deste anno [1894] assumi o cargo no dia immediato [...]. Informei-me do andamento que tinha tido o ensino durante a regencia do meu antecessor [Medeiros e Albuquerque], tendo como resposta que até então nada houvera sido feito [...]. Iniciei o curso pelo estudo da geologia [...]. A segunda parte do curso foi consagrada ao estudo da botanica [...] com maior particularidade dos varios produtos vegetaes de que as bellas artes lançam mão. [...] Terminei o curso dando uma noticia sobre os produtos de origem animal que são empregados nas bellas artes [...] (NERY, 1895, p. 22-24).

Temos algum conhecimento sobre a atuação profissional de Medeiros e Albuquerque, que, segundo consta, foi jornalista, contista, poeta, romancista e teatrólogo, e não nos parece que ele tivesse sido a escolha mais apropriada para a regência de uma cadeira como a de história natural, física e química. Isso nos indica que, para a cadeira não permanecer vaga, deveria ser providenciado um professor dentro dos quadros da própria Escola e, por motivos que não pudemos rastrear, o escolhido foi Medeiros e Albuquerque.

A cadeira de desenho figurado também teve um início conturbado na Escola Nacional de Belas Artes. Em 28 de maio de 
1893, apenas alguns dias após as aulas de desenho figurado serem iniciadas, Pedro Weingärtner solicitou uma licença prolongada, a qual foi sucedida por outras licenças. O pintor retomou o magistério somente em setembro de 1894. Para que tão importante cadeira não ficasse vaga, Modesto Brocos a assumiu interinamente, de maio a agosto de 1893, quando foi substituído por Belmiro de Almeida, que ministrou a cadeira de agosto de 1893 a julho de 1894, um pouco antes do retorno de Weingärtner.

Assim, entre maio de 1893 e setembro de 1894, a disciplina de desenho figurado teve três professores diferentes, que se sucederam em pleno ano letivo, o que, por mais próximas que tenham sido as suas orientações, deve ter causado uma ruptura no processo de ensino e aprendizagem. Esse tipo de substituição, em pleno período letivo, não é considerado pedagogicamente positivo no século XXI e, certamente, não o era na década de 1890, sobretudo quando ocorria em uma disciplina de base, como era o caso do desenho figurado.

O motivo da licença de Weingärtner, por problemas de saúde, pode ser questionado se tivermos em conta que, segundo seus biógrafos, em 1893, ele fez um giro pelo interior do Rio Grande do Sul, a fim de coletar material e apontamentos para uma série de obras dedicadas a temas locais, como Desterro e Revolucionários (TARASANTCHI, 2009, p. 122). A licença de Weingärtner e a atividade que exerceu nesse período, viajar pelo interior do Rio Grande do Sul, parecem não combinar. Henrique Bernardelli foi outro professor que, como Weingärtner, solicitou licenças prolongadas, as quais foram sucessivamente emendadas por outras. Henrique Bernardelli requereu uma licença de seis meses em junho de 1893, que foi prorrogada por um prazo de igual tempo; a segunda prorrogação, em maio de 1894, foi de três meses, seguida por uma terceira prorrogação de dois meses. Ele somente retomou as aulas em outubro de 1894, praticamente no final do ano.

Em carta datada de 30 de março de 1893 e assinada em Roma, Henrique Bernardelli comunicou não poder retornar ao Brasil em tempo devido para a abertura das aulas e solicitou um prolongamento de seis meses da licença de férias, em cujo gozo se achava. Não explicou o motivo que o impossibilitava de retornar ao Brasil, no entanto, Rodolpho Amoêdo, diretor em exercício, que tinha como função deferir ou indeferir os pedidos de licença, acrescentou um comentário à solicitação de Henrique Bernardelli:

O Professor Henrique Bernardelli teve licença para ausentar-se desta Capital durante o período das férias, sem prejuizo 
dos seus vencimentos, segundo os precedentes. O pedido de que trata esta petição é de licença com os descontos da lei e deve ser entendida para tratar de saúde, visto que o requerente em carta particular declarou-me achar-se ainda soffrendo as consequencias pathologicas da febre amarella de que foi accomettido em maio do anno passado nesta cidade. Nada tenho, pois, que oppor à concessão da referida licença (MUSEU D. JOÃO VI, Livro de correspondências, 4 mai. 1893, p. 62B, $\left.{ }_{3} \mathrm{~A}\right)^{2}$.

Culpar a febre amarela, um ano após de ter sido acometido pela doença, pela necessidade de uma licença por seis meses, ainda que sem vencimentos, parece-nos um tanto duvidoso. A intervenção de Amoêdo tem o sentido de reforçar e justificar o pedido do colega. Acreditamos que o real motivo da licença solicitada por Henrique Bernardelli tenha sido a ida a Chicago para participar da Exposição Universal de 1893. Mas se trata, por hora, de uma especulação. Além de o irmão Rodolpho Bernardelli lá se encontrar, Henrique Bernardelli possuía inúmeras telas expostas no evento, entre elas Mater, Messalina, Proclamação da República e Tarantella. Sabemos igualmente que, em 1893, ele alugou um ateliê em Roma, na Villa Strohl-Fern (FEO, 2010, p. 106). Sabemos, igualmente, que, em 1894, quando das últimas prorrogações da sua licença médica, Henrique Bernardelli estava no México, possivelmente visitando seu irmão, Félix Bernardelli, que vivia naquele país (MUSEU DOM JOÃO VI. Livro de correspondências, $1^{\mathrm{o}}$ mai. 1894, p. 74B).

Henrique Bernardelli nunca teve uma posição muito positiva sobre o meio artístico do Rio de Janeiro (BERNARDELLI, H., 1894) e, em mais de um documento, encontramos evidências de que o seu aceite para reger a cadeira de pintura na Escola (BERNARDELLI, H., 1890) e sua consecutiva permanência no Brasil se deviam exclusivamente ao suporte (BERNARDELLI, H., 1895) que julgava ser necessário dar ao irmão Rodolpho Bernardelli, a quem chamava carinhosamente de "Fofo". Reúnam-se a isso as condições nada favoráveis nas quais a Escola funcionava em seus primeiros anos para compreendermos plenamente as licenças mal justificadas, que possibilitavam Henrique Bernardelli de sair, ainda que brevemente, do "parco meio artístico brasileiro".

A cadeira de pintura que Henrique Bernardelli regia ficou vaga em junho e julho de 1893, depois disso foi dividida entre Modesto Brocos e Rodolpho Amoêdo. Se não foi as- 
sumida completamente por Amoêdo, isso se deveu ao fato, possivelmente, de ele já estar bastante atarefado, pois, em 1893, era o diretor interino da Escola Nacional de Belas Artes, substituindo Rodolpho Bernardelli, que se encontrava em Chicago, nos EUA, como membro da Comissão Brasileira da Exposição Universal Colombiana. Por esse motivo, o relatório da cadeira de pintura que pertencia a Henrique Bernardelli foi assinado, em 1893, conjuntamente por Brocos e Amoêdo. Havia, para além da substituição interna dos professores, cadeiras que ficavam vagas por extensos períodos - foi o caso da cadeira de desenho de arquitetura, inativa ao longo de 1894. Também as cadeiras regidas por Henrique Bahiana, noções de topografia, plantas e desenho topográfico e desenho linear - esta última especialmente criada quando da formulação dos estatutos de 1890 -, ficaram desocupadas durante mais de um ano, após o seu pedido de exoneração, em 17 de novembro de 1893 (AMOÊDO, 1894, p. 8)². Bahiana não estava plenamente satisfeito com o andamento da Escola, sobretudo em relação ao pouco tempo destinado às suas disciplinas, tendo ele solicitado, em abril de 1892, que fossem as suas matérias acrescidas de mais uma hora (MUSEU D. JOÃO VI, Ata de 6 abr., 1892, p. 12A).

Os documentos nos revelam que Henrique Bahiana pediu exoneração por ter sido nomeado arquiteto da prefeitura do Rio de Janeiro e não era possível, naquele momento, um funcionário ter mais de um emprego em órgão público.

Ao longo de 1894, foram realizados dois concursos para a cadeira ocupada por Bahiana, a qual permaneceu vaga, pois os candidatos, segundo a banca examinadora do concurso, não apresentavam os requisitos exigidos (MUSEU D. JOÃO VI, Livro de correspondências, 18 jun. 1894, p. 78).

Assim, a disciplina de desenho linear, fundamental para a afirmação e a implementação da Reforma de 1890, sobretudo no que se refere à sua relação com a Reforma Benjamin Constant, ficou sem docente por todo o ano de 1894. Em 2 de outubro de 1894, Henrique Bahiana solicitou o retorno à Escola, e Rodolpho Bernardelli não somente aprovou o seu retorno, mas, literalmente, pediu que ele reassumisse a cadeira, uma vez que não havia sido encontrado um professor qualificado para ela.

À guisa de considerações finais, acreditamos que o texto é relevante pelo seu ineditismo, uma vez que assinalamos as dificuldades enfrentadas pela Escola nos seus primeiros anos de funcionamento, elucidando que, se por um lado, alguns 
objetivos foram alcançados - sobretudo em relação à reorganização da estrutura de ensino -, por outro, velhos desejos levaram alguns anos para serem alcançados, como a obtenção de um novo prédio para abrigar a instituição. Revelamos que a falta de professores e a contínua substituição do corpo docente foram um problema que a Escola Nacional de Belas Artes teve que administrar nos seus primeiros anos de funcionamento. Muitos desses professores que defendemos se ausentavam da Escola em razão das péssimas condições estruturais do prédio que abrigava a instituição. Eram constantes as queixas nesse sentido. Por outro lado, não nos foi possível identificar reclamações de outro cunho por parte, inclusive, de professores como o pintor Modesto Brocos. No livro A questão do ensino de Bellas Artes seguido da crítica sobre a direção Bernardelli e justificação do autor, de 1915, Brocos (1915, p. 44-45) afirmou que o ensino ministrado na instituição "continuou a ser em seu fundo, ensino e disciplinas, pouco mais ou menos do que era no tempo do Império ou, para falar com franqueza, a mesma cousa". No entanto, nos muitos documentos redigidos por ele ao longo dos anos iniciais da Escola, não localizamos nenhuma crítica desse cunho, o que comprova que os motivos que levaram Brocos a criticar a Escola foram por razões muito posteriores. A Escola, assim, modernizou o seu sistema de ensino, mas continuou aprisionada em uma edificação ultrapassada e sem o suporte necessário, por parte do governo, para efetivar as reformas de modo pleno.

NOTAS

1. A carta de Henrique Bernardelli está datada de 30 mar. de 1893, em Roma. Também se encontravam em Roma, no início de 1893, Zeferino da Costa e Belmiro de Almeida, conforme constatamos após a leitura do Livro de correspondências da ENBA de 1893. p. 6oA, 63 B.

2. Amoêdo comunica a exoneração, a pedido do prof. Bahiana em 17 de novembro, e de Zeferino da Costa em 25 de setembro, também a pedido.

\section{Referências}

ALMEIDA, Belmiro de. Pequeno relatório da aula de desenho figurado. In: NASCIMENTO, Alexandre Cassiano do. Relatório do Ministro da Justiça e Negócios Interiores ao Vice-Presidente da República dos Estados Unidos do Brasil, em março de 1894. p. 19-20. Anexo Q. (Relatórios Ministeriais da Escola Nacional de Belas Artes).

AMOÊDO, Rodolpho. Anexo Q. In: NASCIMENTO, Alexan- 
dre Cassiano do. Relatório do Ministro da Justiça e Negócios Interiores ao Vice-Presidente da República dos Estados Unidos do Brasil, em março de 1894. (Relatórios Ministeriais da Escola Nacional de Belas Artes).

Pequeno relatório da aula de pintura. In: FERREIRA, Antonio Gonçalves. Relatório do Ministro da Justiça e Negócios Interiores ao Vice-Presidente da República dos Estados Unidos do Brasil, em abril de 1895. p. 18. Anexo P. (Relatórios Ministeriais da Escola Nacional de Belas Artes). AMOÊDO, Rodolpho; BROCOS, Modesto. Pequeno relatório da aula de pintura. In: NASCIMENTO, Alexandre Cassiano do. Relatório do Ministro da Justiça e Negócios Interiores ao Vice-Presidente da República dos Estados Unidos do Brasil, em março de 1894. p. 28. Anexo Q. (Relatórios Ministeriais da Escola Nacional de Belas Artes).

BERNARDELLI, Henrique. Carta para Eliseu Visconti, 15 jan. 1895. Original transcrito pela professora Ana Maria Tavares Cavalcanti antes da doação dos documentos ao Museu Nacional de Belas Artes pela família Visconti. 1895b. (Arquivo do Museu Nacional de Belas Artes).

. Carta para Eliseu Visconti. Rio de Janeiro, 18 dez. 1894. Original transcrito pela professora Ana Maria Tavares Cavalcanti antes da doação dos documentos ao Museu Nacional de Belas Artes pela família Visconti. (Arquivo do Museu Nacional de Belas Artes).

. Carta para Eliseu Visconti. Rio de Janeiro, 8 fev. 1895. Original transcrito pela professora Ana Maria Tavares Cavalcanti antes da doação dos documentos ao Museu Nacional de Belas Artes pela família Visconti. 1895a. (Arquivo do Museu Nacional de Belas Artes).

. Carta para Zeferino da Costa. Roma, 30 nov. 1890. Arquivo do Museu Nacional de Belas Artes, Pasta Henrique e Rodolpho Bernardelli, APO 101.

Pequeno relatório da aula de pintura. In: FERREIRA, Antonio Gonçalves. Relatório do Ministro da Justiça e Negócios Interiores ao Vice-Presidente da República dos Estados Unidos do Brasil, em abril de 1895. 1895c. p. 17-18. Anexo P. (Relatórios Ministeriais da Escola Nacional de Belas Artes). BERNARDELLI, Rodolpho. Relatório apresentado ao Presidente da República dos Estados Unidos do Brasil pelo Dr. João Barbalho Uchôa Cavalcanti, Ministro da Instrução Pública, Correios e Telégrafos, em maio de 1891. Anexo H. (Relatórios Ministeriais da Escola Nacional de Belas Artes). Anexo P. In: FERREIRA, Antonio Gonçalves. Relató- 
rio do Ministro da Justiça e Negócios Interiores ao Vice-Presidente da República dos Estados Unidos do Brasil, em abril de 1895. 1895a. (Relatórios Ministeriais da Escola Nacional de Belas Artes).

. Carta para o Dr. Antonio Gonçalves Ferreira. Rio de Janeiro, 21 jan. 1895. In: FERREIRA, Antonio Gonçalves. Relatório do Ministro da Justiça e Negócios Interiores ao Vice-Presidente da República dos Estados Unidos do Brasil, em abril de 1895. 1895b. p. 231-232. (Relatórios Ministeriais da Escola Nacional de Belas Artes).

BROCOS, Modesto. Pequeno relatório da aula de pintura. In: FERREIRA, Antonio Gonçalves. Relatório do Ministro da Justiça e Negócios Interiores ao Vice-Presidente da República dos Estados Unidos do Brasil, em abril de 1895. p. 17. Anexo P. (Relatórios Ministeriais da Escola Nacional de Belas Artes).

. A questão do ensino de bellas artes, seguido da crítica sobre a direção de Bernardelli e justificação do autor. Rio de Janeiro: [s.n.], 1915.

CAVALCANTI, Ana Maria T. Os embates no meio artístico carioca em 1890 - antecedentes da Reforma da Academia das Belas Artes. 19E20, Rio de Janeiro, v. II, n. 2, abr. 2007. Disponível em: <http://www.dezenovevinte.net/criticas/ embate_189o.htm>.

DAZZI, Camila. Pai e construtor da arte brasileira. A Academia das Belas Artes na reforma da educação promovida por Benjamin Constant em 1890/1891. Revista Digital do LAV, v. 10, 2013.

. Pôr em prática a reforma da antiga Academia: a concepção e a implementação da reforma que instituiu a Escola Nacional de Belas Artes em 1890. 2011. Tese (Doutorado em História da Arte) - Programa de Pós-Graduação de Artes Visuais da Universidade Federal do Rio de Janeiro, Rio de Janeiro, 2011.

DUQUE, Gonzaga. A arte brasileira. Rio de Janeiro: H. Lombaerts, 1888. Disponível em: <http://www.dezenovevinte. net $/>$.

FEO, Giovanna Caterina de. Alfred Wilhelm Strohl-Fern. Roma: Davide Ghaleb Editore, 2010.

LOBO, Fernando. Relatório do Ministro da Justiça e Negócios Interiores ao Vice-Presidente da República dos Estados Unidos do Brasil, em abril de 1893. p. 213. (Relatórios Ministeriais da Escola Nacional de Belas Artes).

MENDES JR., Antonio; MARANHÃO, Ricardo. Brasil história: 
texto e consulta. República Velha. São Paulo: Brasiliense, 1981. v. 3.

MUSEU D. JOÃO VI. Escola de Belas Artes. Universidade Federal do Rio de Janeiro. Atas da Escola Nacional de Belas Artes. Ata de 19 jul. 1893. p. 22B.

. Atas da Escola Nacional de Belas Artes. Ata de 25 set. 1891. p. 8.

. Atas da Escola Nacional de Belas Artes. Ata de 4 jun. 1891. p. 2 B.

. Atas da Escola Nacional de Belas Artes. Ata de 6 abr. 1891. p. 12A.

. Atas da Escola Nacional de Belas Artes. Ata de 6 abr. 1892. p. 12A.

. Livros de correspondência. Livro de correspondências referente a $1^{\circ}$ mar. 1892 . p. 30 A.

. Livros de correspondência. Livro de correspondências referente a 10 mar. 1891. p. 5 .

. Livros de correspondência. Livro de correspondências referente a 26 mar. 1894. p. 73A.

. Livros de correspondência. Livro de correspondências referente a 13 abr. 1892. Contrato de 8 mar. 1892. p. 32 A e B. . Livros de correspondência. Livro de correspondências referente a 25 abr. 1894. p. 74A.

. Livros de correspondência. Livro de correspondências referente a $1^{\circ}$ maio 1894 . Pedido de prorrogação de três meses de licença feito por Henrique Bernardelli. p. 74 B.

. Livros de correspondência. Livro de correspondências referente a 4 maio 1893. Cartas de Zeferino da Costa e Belmiro de Almeida, datas do início de 1893, Roma. P. 62B, 63A.

Livros de correspondência. Livro de correspondências referente a 10 jun. 1893. p. 22A.

. Livros de correspondência. Livro de correspondências referente a 18 jun. 1894. Autorização para se fazer um novo concurso para o lugar do Henrique Bahiana. p. 78.

. Livros de correspondência. Livro de correspondências referente a 26 jun. 1892. p. 36B.

. Livros de correspondência. Livro de correspondências referente a 13 ago. 1892. p. 39B.

. Livros de correspondência. Livro de correspondências referente a 6 set. 1892. p. 4oB.

. Livros de correspondência. Livro de correspondências referente a 8 nov. 1893. p. 68A.

. Livros de correspondência. Livro de correspondên- 
cias referente a 9 nov. 1891. p. 20 A.

. Livros de correspondência. Livro de correspondên-

cias referente a 16 nov. 1891. Contrato de 29 set. 1891. p. 20A e B, $21 \mathrm{~A}$ e $\mathrm{B}$.

NASCIMENTO, Alexandre Cassiano do. Relatório do Ministro da Justiça e Negócios Interiores ao Vice-Presidente da República dos Estados Unidos do Brasil, em março de 1894. p. 253. (Relatórios Ministeriais da Escola Nacional de Belas Artes).

NERY, Márcio. Pequeno relatório da aula de história natural, física e química. In: FERREIRA, Antonio Gonçalves. Relatório do Ministro da Justiça e Negócios Interiores ao Vice-Presidente da República dos Estados Unidos do Brasil, em abril de 1895. p. 22-24. Anexo P. (Relatórios Ministeriais da Escola Nacional de Belas Artes).

TARASANTCHI, Ruth Sprung. Minha descoberta de Pedro Weingärtner. In: Pedro Weingärtner 1853-1929: um artista entre o Velho e o Novo Mundo. São Paulo: Pinacoteca do Estado de São Paulo, 200

Recebido em: 28/04/2015

Aceito em: 14/02/2017

\section{CAMILA DAZZI}

camiladazzi@gmail.com

Pós-doutorado (CAPES) junto à Università degli Studi di Napoli Federico II/Itália (2013). Doutora em Teoria da Arte - História e Crítica pelo Programa de Pós-Graduação da Escola de Belas Artes da UFRJ (2011). Mestre em História da Arte pelo Programa de Pós-Graduação do Instituto de Filosofia e Ciências Humanas da UNICAMP (2006) e graduada em Artes Plásticas pela Universidade Federal do Rio de Janeiro (2003). É professora do Centro Federal de Educação Tecnológica (RJ), lecionando no Mestrado em Relações Étnico-raciais, na Linha de História da Arte, e na Graduação, no campus Nova Friburgo. É editora responsável pela revista 19\&20 (QUALIS B2-Artes) e organizadora dos livros: Oitocentos - Arte Brasileira do Império à República. Tomo I; Oitocentos. Tomo II e Oitocentos - Intercâmbios Culturais entre Brasil e Portugal. Tomo III (2013). É autora de artigos publicados em periódicos de conhecida importância no campo da Arte, além de ensaios e estudos em obras coletivas. Temas de Pesquisa principais: Arte Brasileira do século XIX e Início do XX, Ensino Artístico Oitocentista, Crítica e Teoria da Arte do século XIX, Relações entre Brasil e Itália na Arte Oitocentista. 